\title{
Performance investigation of an advanced tracked prime mover on the low bearing soil
}

\begin{abstract}
This study has presented a performance investigation of an advanced tracked prime mover for the operation of agricultural goods and other operations on peat terrain. The maximum and continuous traction torque of the prime mover has been developed by designing an advanced controller for controlling the intelligent system. The prime mover's mobility is studied with ultrasonic displacement sensor, torque transducer, National Instrument cRIO-9004 CompactRIO Real-time Controller Unit (RCU), a National Instrument TPC 2106T Touch Panel Control (TPC), a Trimble AG132 GPS antenna and receiver unit, and a Dlink DIR-655 router. The fuzzy logic controller (FLC) has been equipped with the prime mover hydraulic system to increase the traction torque of the hydraulic motor when the prime mover's sinkage is more than or equal to $70 \mathrm{~mm}$. The prime mover's design demonstrates good potential in traversing peat terrain as the measured tractive effort was found to be $48 \%$ of the vehicle's gross weight while the recommended tractive effort is in the range of $30-36 \%$ of the vehicle's gross weight.
\end{abstract}

Keyword: Traction; Fuzzy logic controller; Hydraulic electronic control unit; Two-phase cooling system 